\title{
A comparative study of reaction time, dynamic balance and co- ordination among the players of hockey, volleyball, football and cricket players
}

- PRAMODKUMAR SAHADEORAO BHALERAO

Received : 17.12.2014; Revised : 15.02.2015; Accepted : 01.03 .2015

Author for correspondence

PRAMODKUMAR

SAHADEORAO BHALERAO

Degree College of Physical

Education, Shree Hanuman Vyayam

Prasarak Mandal, AMRAVATI (M.S.)

INDIA

\section{-ABSTRACT}

The present study was carried out with a view to compare the reaction time, balance and coordination of the hockey, volleyball, football and cricket players. It was hypothesised that there might be significant difference in reaction time, dynamic balance and co-ordination of hockey, volleyball, football and cricket players. For the purpose of the study total 60 subjects were randomly selected from Degree College of Physical Education, Amravati 15 subjects from each game of hockey, volleyball, football and cricket. The minimum study of participation was intercollegiate level and the age of the subject ranged between 18 to 25 years only male players were chosen for the study. The subjects were tested on reaction time measured in second using Nelson's hand reaction time test, dynamic balance measured in points using modified bass test of dynamic balance and coordination measured in seconds using eye hand and eye foot co-ordination test. To analyze the collection of data the one way analysis of variance and L.S.D. Post Hoc Test statistical techniques were employed. The findings of the statistical analysis revealed that the Hand reaction time $(\mathrm{F}=$ 2.97), Foot reaction time ( $\mathrm{F}=4.79)$, Dynamic balance $(\mathrm{F}=5.47)$ and Eye hand co-ordination $(\mathrm{F}=3.46)$ showed significant differences among hockey, volleyball, football and cricket, whereas Eye foot coordination $(\mathrm{F}=0.55)$ did not show significant difference among the selected players of different games. From the findings of L.S.D. Post hoc test it is also learnt that hockey players were significantly superior than the football players in hand reaction time. Football players were significantly superior than hockey, volleyball and cricket players in foot reaction time football players significantly superior than the hockey and cricket players and dynamic balance, in case of eye hand co-ordination the hockey players showed superior performance than the volleyball and cricket players which was statistically significant.

- KEY WORDS : Reaction time, Dynamic balance, Co-ordination, Performance

- HOW TO CITE THIS PAPER : Bhalerao, Pramodkumar Sahadeorao (2015). A comparative study of reaction time, dynamic balance and co-ordination among the players of hockey, volleyball, football and cricket players. Internat. J. Phy. Edu., 8 (1) : 1-7. 